Andriy Zhydkov, Mirjam Christ-Crain, Robert Thomann, Claus Hoess, Christoph Henzen, Werner Zimmerli, Beat Mueller and Philipp Schuetz*, for the ProHOSP Study Group

\title{
Utility of procalcitonin, C-reactive protein and white blood cells alone and in combination for the prediction of clinical outcomes in community- acquired pneumonia
}

DOI 10.1515/cclm-2014-0456

Received April 28, 2014; accepted June 13, 2014; previously published online July 11, 2014

\section{Abstract}

Background: The added value of biomarkers, such as procalcitonin (PCT), C-reactive protein (CRP), and white blood cells (WBC), as adjuncts to clinical risk scores for predicting the outcome of patients with community-acquired pneumonia (CAP) is in question. We investigated the prognostic accuracy of initial and follow-up levels of inflammatory biomarkers in predicting death and adverse clinical outcomes in a large and well-defined cohort of CAP patients. Methods: We measured PCT, CRP and WBC on days 1, 3, 5, and 7 and followed the patients over 30 days. We applied multivariate regression models and area under the curve (AUC) to investigate associations between these biomarkers, the clinical risk score CURB-65, and clinical outcomes [i.e., death and intensive care unit (ICU) admission].

Results: Of 925 patients with CAP, 50 patients died and 118 patients had an adverse clinical outcome. None of the initial biomarker levels significantly improved the

\footnotetext{
*Corresponding author: Prof. Philipp Schuetz, Medical University Clinic, Kantonsspital Aarau, Tellstr. 5, 5001 Aarau, Switzerland, Phone: +41 628389524, Fax: +41 628386945,

E-mail: philipp.schuetz@ksa.ch

Andriy Zhydkov and Beat Mueller: University Department of Medicine, Kantonsspital Aarau, Aarau, Switzerland

Mirjam Christ-Crain: Division of Endocrinology, Diabetes and Clinical Nutrition, Department of Internal Medicine, Universitätsspital Basel, Basel, Switzerland

Robert Thomann: Department of Internal Medicine, Bürgerspital Solothurn, Solothurn, Switzerland

Claus Hoess: Department of Internal Medicine, Kantonsspital Münsterlingen, Münsterlingen, Switzerland

Christoph Henzen: Department of Internal Medicine, Luzerner Kantonsspital, Luzern, Switzerland

Werner Zimmerli: Basel University Medical Clinic, Liestal, Switzerland
}

CURB-65 score for mortality prediction. Follow-up biomarker levels showed significant independent association with mortality at days 3, 5, and 7 and with improvements in AUC. Initial PCT and CRP levels were independent prognostic predictors of adverse clinical outcome, and levels of all biomarkers during the course of disease provided additional prognostic information.

Conclusions: This study provides robust insights into the added prognostic value of inflammatory markers in CAP. Procalcitonin, CRP, and to a lesser degree WBC provided some prognostic information on CAP outcomes, particularly when considering their kinetics at days 5 and 7 and when looking at adverse clinical outcomes instead of mortality alone.

Keywords: community-acquired pneumonia (CAP); C-reactive protein (CRP); CURB-65 score; mortality; procalcitonin; severity of illness; white blood cells.

\section{Introduction}

Community-acquired pneumonia (CAP) continues to be a worldwide health problem, particularly as a leading source of infections with high mortality [1]. The incidence of CAP in Europe ranges from 1.2 to 11.6 cases per 1000 population per year [2] with rates of hospitalization ranging from $40 \%$ to $60 \%$ [3]. Although the elderly and patients with comorbidities have a 10-fold higher risk for CAP, sporadic viral pneumonia can sometimes be fatal in over $50 \%$ of younger patients $10-39$ years of age $[4,5]$.

Diagnosis, severity assessment, and prediction of outcome in patients with CAP are challenging and often based on clinical experience, and not on scientific evidence. Clinical severity scores, such as the pneumonia severity index (PSI), the 'confusion, urea, respiratory, and blood pressure' (CURB) score, and its modification the CURB-65 (CURB plus age $>65$ ), may provide a more 
objective initial severity assessment for mortality prediction and are thus recommended by guidelines [6]. However, these scores have important limitations, such as only moderate prognostic accuracy, validation only for mortality but not for other adverse clinical outcomes, and lack of inclusion of novel biomarkers reflecting the inflammatory response and/or infection severity. Several smaller studies have suggested that the addition of biomarkers, such as C-reactive protein (CRP) [7] and procalcitonin (PCT) [8] may further improve these scores. However, most previous studies had small sample sizes and/or were limited to measurement of biomarkers only once upon admission.

The aim of the current analysis was to take advantage of a large multicenter cohort to investigate the prognostic value of levels of these biomarkers and white blood cells (WBC) both at admission and during follow-up as adjuncts to the CURB65 score for prediction of mortality and adverse clinical outcomes.

\section{Materials and methods}

\section{Setting and study population}

The present study analyzed data from the procalcitonin guided antibiotic therapy and hospitalization in patients with lower respiratory tract infections (ProHOSP) study using 925 patients with radiologically confirmed CAP. A detailed description of this study has been published elsewhere $[9,10]$ and is also available in the clinicaltrials. gov database (NCT00350987). Full ethical approval for this trial was obtained from all Local Ethical Committees, and all patients gave written informed consent.

In brief, patients with lower respiratory tract infections (LRTI) including CAP admitted to emergency departments at 1 out of 6 hospitals in Switzerland between December 2006 and March 2008 were consecutively included. A study website provided information on the evidence-based management of all patients based on the most recent guidelines [6, 11]. For all patients with CAP, the study protocol explicitly specified the need for X-ray confirmation and for collection of two sets of pre-treatment blood cultures. Thus, two pairs of blood cultures for both aerobic and anaerobic conditions were collected and processed using an automated colorimetric detection system (BacT/ ALERT, bioMerieux, Durham, NC, USA) in three hospitals and an equivalent blood culture system (BACTEC Becton-Dickinson, Cockeysville, MD, USA) in the other three hospitals [12]. If blood culture bottles indicated bacterial growth, samples were Gram stained and subcultured. The correct identification of the pathogen was achieved according to routine laboratory procedures. There was no recommendation for or against viral testing as the main trial focus was on bacterial CAP.

Inclusion criteria for patients were: written informed consent, age $\geq 18$ years, and admission from the community or a nursing home with the main diagnosis of CAP. Exclusion criteria were the inability to provide written informed consent, insufficient German language skills, active intravenous drug use, previous hospitalization within 14 days, severe immunosuppression other than that induced by corticosteroids, accompanying chronic infection or endocarditis, and severe medical co-morbidity where death was imminent. Diagnosis of CAP required the presence of at least one respiratory symptom (cough with or without sputum production, dyspnea, tachypnea, or pleuritic chest pain) in addition to one auscultatory finding or sign of infection (core body temperature $>38.0^{\circ} \mathrm{C}$, shivers, or white blood count $>10 \mathrm{~g} / \mathrm{L}$ or $<4 \mathrm{~g} / \mathrm{L}$ cells) and a new infiltrate on chest radiograph [6].

In all patients, baseline assessments included collection of clinical data and vital signs, confirmation of the presence or absence of comorbid conditions, and a routine blood test. Patients were followed during the hospital stay and blood specimens were sampled for PCT, CRP, and WBCs upon hospital admission, on days 3, 5 and 7, and on the day of discharge. Serum PCT was measured with a highly sensitive time-resolved amplified cryptate emission (TRACE) technology assay (PCT Kryptor, B.R.A.H.M.S. AG, Hennigsdorf, Germany). The assay has a detection limit of $0.02 \mu \mathrm{g} / \mathrm{L}$ and a functional assay sensitivity of $0.06 \mu \mathrm{g} / \mathrm{L}$ (i.e., 3 - to 10 -fold above normal mean values). Serum CRP concentrations were determined by an enzyme immunoassay having a detection limit of $<5 \mathrm{mg} / \mathrm{dL}$ (EMIT, Merck Diagnostica, Zurich, Switzerland). The CURB-65 score was calculated at admission in all patients as recommended [13, 14].

We performed blinded telephone interviews with all patients 30 days after inclusion for assessment of vital status and other secondary endpoints.

\section{Statistical considerations and analysis}

The primary endpoint of this analysis was all-cause mortality within 30 days. Secondary endpoints included serious adverse events defined as death or intensive care unit (ICU) admission.

Discrete variables are expressed as counts (percentage) and continuous variables as medians and interquartile ranges (IQR). Frequency comparison was done using the $\chi^{2}$-test. The two-group comparison for continuous data was done with the Mann-Whitney U-test. We used univariate and multivariate logistic regression analysis to study the association between biomarker levels and outcome adjusting the models for the CAP severity score CURB-65 [15]. Area under the receiver-operating-characteristics curve (AUC) was calculated to assess overall discrimination using STATA 9.2 (Stata Corp, College Station, TX, USA). All statistical tests were two-tailed and p-values $<0.05$ were considered to indicate statistical significance.

\section{Results}

This analysis includes 925 patients with a final diagnosis of CAP. The median age was 73 years and most patients suffered from at least one comorbidity including chronic heart failure $(17 \%)$, cerebrovascular disease $(9 \%)$, diabetes $(17 \%)$, and chronic renal failure (23\%). Risk assessment on admission showed that $50.4 \%$ of patients were in the high-risk CURB-65 category with scores of $\geq 2$ points. At the 30-day follow-up, 118 patients had a serious 
adverse event defined as mortality (35 patients, 3.8\%), ICU admission (68 patients, 7.4\%) or both (15 patients, 1.6\%). Table 1 shows pertinent patient characteristics of the overall cohort and categorized by survival status. Admission PCT levels were significantly higher in non-survivors as compared to survivors [0.83 ng/L (IQR 0.30-5.66) vs. 0.46 (IQR 0.15-2.61); $\mathrm{p}=0.023$ ]. There was no difference between these two groups with regard to admission CRP and WBC levels.

We used univariate and multivariate logistic regression models to investigate associations between admission and follow-up biomarker levels and outcome (Table 2). In univariate analysis, admission PCT levels were significant predictors of 30-day mortality on admission [unadjusted odds ratio (OR) per unit increase of log transformed PCT 1.19 (95\% CI 1.03-1.38); AUC 0.60]. However, this association was no longer significant after adjustment for the CURB-65 score. No significant association of admission CRP levels [unadjusted OR 1.01 (95\%
0.77-1.33); AUC 0.45] or WBC counts [unadjusted OR 1.01 (95\% 0.56-1.86); AUC 0.52] with outcome was found.

Consideration of follow-up biomarker levels and kinetics of the biomarkers from admission through days 3, 5, and 7 revealed all biomarkers as having a better association with outcome compared to initial levels alone (Table 2). The AUC of PCT was 0.61, 0.68, and 0.73 at days 3, 5 and 7 , respectively, while the differences in AUC between admission and these three time points were $0.69,0.65$, and 0.71 , respectively. The corresponding results for CRP were 0.62 , 0.68 , and 0.78 for days 3, 5 and 7, and 0.50, 0.44, and 0.62 for the differences, respectively. For WBC, the AUC values were $0.67,0.65$, and 0.77 on days 3,5 , and 7 , respectively, while the respective differences were $0.67,0.58$, and 0.79 .

Table 3 shows the results of a similar analysis for serious adverse events. In this case, the prognostic potential for all biomarkers was better compared to survival prediction and was also significant after adjusting for the CURB-65 score.

Table 1 Baseline characteristics of the study participants $(n=925)$.

\begin{tabular}{|c|c|c|c|c|}
\hline & All patients (925) & Survivors (875) & Non-survivors (50) & p-Value \\
\hline \multicolumn{5}{|l|}{ Demographic characteristics } \\
\hline Age, years & $73(59-82)$ & $72(57-82)$ & $81(75-85)$ & $<0.0001$ \\
\hline Sex (men), n (\%) & $544(58.8)$ & $511(58.4)$ & $33(66.0)$ & 0.28 \\
\hline \multicolumn{5}{|l|}{ Coexisting illnesses, n (\%) } \\
\hline Chronic heart failure & $159(17.2)$ & $143(16.3)$ & $16(32.0)$ & 0.0043 \\
\hline Cerebrovascular disease & $82(8.9)$ & $77(8.8)$ & $5(10.0)$ & 0.7718 \\
\hline Renal dysfunction & $206(22.3)$ & $177(20.2)$ & $29(58.0)$ & $<0.0001$ \\
\hline Neoplastic disease & $118(12.8)$ & $107(12.2)$ & $11(22.0)$ & $<0.05$ \\
\hline Diabetes & $162(17.5)$ & $152(17.4)$ & $10(20.0)$ & 0.63 \\
\hline \multicolumn{5}{|l|}{ Complains, n (\%) } \\
\hline Cough & $762(82.4)$ & $721(82.4)$ & $41(82.0)$ & 0.14 \\
\hline Sputum production & $437(47.2)$ & $409(46.7)$ & $28(56.0)$ & 0.08 \\
\hline Dyspnea & $696(75.2)$ & $654(74.7)$ & $42(84.0)$ & 0.0006 \\
\hline Fever & $618(66.8)$ & $595(68.0)$ & $23(46.0)$ & 0.001 \\
\hline Chills & $301(32.5)$ & $291(33.3)$ & $10(20.0)$ & 0.079 \\
\hline \multicolumn{5}{|l|}{ Clinical findings } \\
\hline Confusion, n (\%) & $74(8.0)$ & $64(7.3)$ & $10(20.0)$ & 0.003 \\
\hline Respiratory rate, breaths/min & $20(16-25)$ & $20(16-25)$ & $24(19-30)$ & 0.02 \\
\hline Systolic blood pressure, $\mathrm{mmHg}$ & $132(119-148)$ & $132(120-149)$ & $120(100-140)$ & $<0.01$ \\
\hline Heart rate, beats/min & $95(82-108)$ & $95(82-108)$ & $98(75-108)$ & 0.35 \\
\hline Body temperature, ${ }^{\circ} \mathrm{C}$ & $38.1(37.2-38.9)$ & $38.1(37.3-38.9)$ & $37.4(36.7-38.6)$ & $<0.01$ \\
\hline Rales, n (\%) & $894(96.6)$ & $599(68.5)$ & $37(74.0)$ & 0.24 \\
\hline \multicolumn{5}{|l|}{ Laboratory findings } \\
\hline Procalcitonin (PCT), ng/L & $0.46(0.15-2.66)$ & $0.46(0.15-2.61)$ & $0.83(0.30-5.66)$ & 0.023 \\
\hline C-reactive protein, $\mathrm{mg} / \mathrm{dL}$ & $155(75-252)$ & $155.5(74.4-252)$ & $153(75-258)$ & 1.0 \\
\hline White blood cells, WBC & $12(9-16.4)$ & $12(9-16.4)$ & $12.2(9.5-16.9)$ & 0.72 \\
\hline \multicolumn{5}{|l|}{ CURB-65 scores } \\
\hline $0-1$ & $459(49.6)$ & $450(51.4)$ & $9(18.0)$ & $<0.001$ \\
\hline 2 & $306(33.1)$ & $284(32.5)$ & $22(44.0)$ & 0.092 \\
\hline $3-4$ & $160(17.3)$ & $141(16.1)$ & $19(38.0)$ & $<0.001$ \\
\hline
\end{tabular}

CURB-65, confusion, urea, respiratory, blood pressure, age 65 years or older. 
Table 2 Association of biomarker levels and survival.

\begin{tabular}{|c|c|c|c|c|c|}
\hline & & & & & Mortality \\
\hline & Unadjusted OR (95\%) & p-Value ${ }^{a}$ & AUC & Adjusted OR $(95 \% \mathrm{Cl})^{\mathrm{b}}$ & p-Value ${ }^{a}$ \\
\hline \multicolumn{6}{|c|}{ Laboratory findings } \\
\hline \multicolumn{6}{|c|}{ РСТ (per 10-fold increase) } \\
\hline Day 1 & $1.19(1.03-1.38)$ & 0.019 & 0.595 & $1.06(0.90-1.25)$ & 0.439 \\
\hline Day 3 & $1.26(1.03-1.54)$ & 0.023 & 0.609 & $1.14(0.92-1.41)$ & 0.222 \\
\hline Day 5 & $1.40(1.08-1.80)$ & 0.009 & 0.680 & $1.30(0.99-1.71)$ & 0.056 \\
\hline Day 7 & $1.69(1.27-2.24)$ & $<0.001$ & 0.733 & $1.67(1.25-2.23)$ & 0.001 \\
\hline \multicolumn{6}{|c|}{ Difference in PCT level from admission } \\
\hline Day 3 & $1.35(1.06-1.71)$ & 0.013 & 0.688 & $1.31(1.03-1.67)$ & 0.030 \\
\hline Day 5 & $1.23(0.91-1.66)$ & 0.178 & 0.649 & $1.22(0.90-1.66)$ & 0.204 \\
\hline Day 7 & $1.43(1.02-2.00)$ & 0.038 & 0.707 & $1.42(1.00-2.00)$ & 0.044 \\
\hline \multicolumn{6}{|l|}{ CRP } \\
\hline Day 1 & $1.01(0.77-1.33)$ & 0.933 & 0.450 & $0.99(0.75-1.30)$ & 0.933 \\
\hline Day 3 & $1.51(0.94-2.43)$ & 0.090 & 0.621 & $1.40(0.86-2.27)$ & 0.171 \\
\hline Day 5 & $1.95(1.20-3.15)$ & 0.007 & 0.680 & $1.92(1.15-3.19)$ & 0.013 \\
\hline Day 7 & $3.31(1.79-6.12)$ & $<0.001$ & 0.780 & $3.46(1.82-6.56)$ & $<0.001$ \\
\hline \multicolumn{6}{|c|}{ Difference in CRP level from admission } \\
\hline Day 3 & $1.00(0.67-1.49)$ & 0.995 & 0.503 & $1.02(0.68-1.52)$ & 0.939 \\
\hline Day 5 & $0.84(0.48-1.46)$ & 0.530 & 0.438 & $0.85(0.48-1.52)$ & 0.585 \\
\hline Day 7 & $1.61(0.66-3.94)$ & 0.297 & 0.622 & $1.38(0.52-3.65)$ & 0.513 \\
\hline \multicolumn{6}{|l|}{ WBC } \\
\hline Day 1 & $1.01(0.56-1.86)$ & 0.954 & 0.515 & $0.98(0.54-1.80)$ & 0.971 \\
\hline Day 3 & $2.80(1.56-5.05)$ & 0.001 & 0.665 & $2.65(1.14-2.82)$ & 0.002 \\
\hline Day 5 & $3.17(1.51-6.67)$ & 0.002 & 0.653 & $2.89(1.29-6.48)$ & 0.010 \\
\hline Day 7 & $8.43(2.50-28.37)$ & 0.001 & 0.773 & $8.12(2.42-27.25)$ & 0.001 \\
\hline \multicolumn{6}{|c|}{ Difference in WBC level from admission } \\
\hline Day 3 & $1.56(0.94-2.58)$ & 0.083 & 0.672 & $1.73(0.98-3.04)$ & 0.059 \\
\hline Day 5 & $1.28(0.75-2.19)$ & 0.371 & 0.579 & $1.27(0.73-2.19)$ & 0.397 \\
\hline Day 7 & $3.88(1.23-12.23)$ & 0.020 & 0.794 & $3.74(1.21-11.61)$ & 0.022 \\
\hline
\end{tabular}

AUC, area under the curve; CRP, C-reactive protein; OR, odds ratio; PCT, procalcitonin; WBC, white blood cells. ${ }^{\mathrm{p}}$-Values are derived from

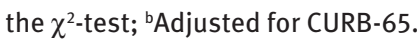

Finally, we also investigated the potential of the different markers assayed on admission and during follow-up to improve prognostication performed using the clinical CURB-65 score alone. This was done by using multivariate logistic regression models to compare the AUC of the CURB-65 score alone with the AUC of the CURB-65 score in combination with levels of each biomarker individually and all together (Table 4). When looking at levels of these biomarkers at admission, PCT, CRP, and the combination of all biomarkers together improved the AUC of the CURB-65 score for prediction of adverse clinical outcome (from AUC 0.68 to 0.74 ). The same was not applicable for mortality prediction, where no significant improvements in AUC based on admission biomarker levels could be observed. Examination of improvements in AUC based on follow-up biomarker levels revealed the most significant improvements to have occurred on days 5 and 7 for both survival prediction and adverse clinical outcome.

\section{Discussion}

The added value of prognostic information derived from inflammatory biomarkers in addition to established clinical scores remains a topic of debate, with multiple smaller studies providing somewhat heterogeneous results. Viewed in this context, the findings of our study conducted in a large and well-characterized CAP cohort are important and provide information on the value not only of initial but also of follow-up biomarker levels. The main findings of this study are three-fold. First, initial biomarker levels provide only limited information to assist with mortality prediction and do not improve prognostic capacity of the CURB-65 score. Second, considering the kinetics of the markers, PCT, CRP and to a lesser degree WBC provide additional prognostic information for mortality risk prediction. Third, all biomarkers combined and added to the CURB-65 score improve the ability to identify patients at risk for adverse clinical outcomes when 
Table 3 Association of biomarker levels and adverse clinical outcomes.

\begin{tabular}{|c|c|c|c|c|c|}
\hline & \multicolumn{5}{|c|}{ Death and ICU admission } \\
\hline & Odds ratio $(95 \%)$ & p-Value ${ }^{a}$ & AUC & Adjusted OR & Adjusted p-Value \\
\hline \multicolumn{6}{|c|}{ Laboratory findings } \\
\hline \multicolumn{6}{|c|}{ PCT } \\
\hline Day 1 & $1.34(1.21-1.49)$ & $<0.001$ & 0.655 & $1.25(1.12-1.40)$ & $<0.001$ \\
\hline Day 3 & $1.44(1.27-1.64)$ & $<0.001$ & 0.674 & $1.37(1.20-1.57)$ & $<0.001$ \\
\hline Day 5 & $1.64(1.41-1.92)$ & $<0.001$ & 0.711 & $1.57(1.34-1.84)$ & $<0.001$ \\
\hline Day 7 & $1.72(1.44-2.05)$ & $<0.001$ & 0.695 & $1.67(1.40-2.00)$ & $<0.001$ \\
\hline \multicolumn{6}{|c|}{ Difference in PCT level from admission } \\
\hline Day 3 & $1.37(1.16-1.62)$ & $<0.001$ & 0.693 & $1.34(1.13-1.59)$ & 0.001 \\
\hline Day 5 & $1.60(1.25-2.06)$ & $<0.001$ & 0.782 & $1.59(1.24-2.05)$ & $<0.001$ \\
\hline Day 7 & $1.56(1.21-2.03)$ & 0.001 & 0.764 & $1.56(1.20-2.03)$ & 0.001 \\
\hline \multicolumn{6}{|l|}{ CRP } \\
\hline Day 1 & $1.61(1.27-2.04)$ & $<0.001$ & 0.638 & $1.59(1.26-2.02)$ & $<0.001$ \\
\hline Day 3 & $1.97(1.44-2.70)$ & $<0.001$ & 0.663 & $1.90(1.39-2.62)$ & $<0.001$ \\
\hline Day 5 & $2.05(1.53-2.74)$ & $<0.001$ & 0.679 & $2.03(1.50-2.75)$ & $<0.001$ \\
\hline Day 7 & $1.76(1.36-2.28)$ & $<0.001$ & 0.661 & $1.75(1.35-2.28)$ & $<0.001$ \\
\hline \multicolumn{6}{|c|}{ Difference in CRP level from admission } \\
\hline Day 3 & $1.14(0.83-1.57)$ & 0.423 & 0.544 & $1.16(0.83-1.60)$ & 0.385 \\
\hline Day 5 & $1.19(0.74-1.91)$ & 0.467 & 0.561 & $1.22(0.75-1.97)$ & 0.420 \\
\hline Day 7 & $1.30(0.65-2.61)$ & 0.463 & 0.557 & $1.21(0.59-2.49)$ & 0.606 \\
\hline \multicolumn{6}{|l|}{ WBC } \\
\hline Day 1 & $0.86(0.57-1.29)$ & 0.461 & 0.494 & $0.83(0.55-1.25)$ & 0.376 \\
\hline Day 3 & $2.27(1.48-3.49)$ & $<0.001$ & 0.630 & $2.19(1.40-3.41)$ & 0.001 \\
\hline Day 5 & $4.18(2.35-7.39)$ & $<0.001$ & 0.709 & $4.21(2.32-7.65)$ & $<0.001$ \\
\hline Day 7 & $5.49(2.72-11.10)$ & $<0.001$ & 0.701 & $5.42(2.66-11.03)$ & $<0.001$ \\
\hline \multicolumn{6}{|c|}{ Difference in WBC level from admission } \\
\hline Day 3 & $1.28(0.90-1.82)$ & 0.164 & 0.590 & $1.38(0.93-2.03)$ & 0.106 \\
\hline Day 5 & $1.39(1.00-1.94)$ & 0.049 & 0.623 & $1.42(1.01-2.00)$ & 0.047 \\
\hline Day 7 & $1.51(0.99-2.31)$ & 0.054 & 0.633 & $1.50(0.98-2.29)$ & 0.064 \\
\hline
\end{tabular}

Adjusted OR, odds ratio adjusted for CURB-65; Adjusted p-Value, p-Value adjusted for CURB-65; AUC, area under the curve; CRP, C-reactive protein; ICU, intensive care unit; PCT, procalcitonin; WBC, white blood cells. ${ }^{\text {a }}$-Values are derived from the $\chi^{2}$-test.

compared with the CURB-65 score alone, both on admission and to a greater extent if the kinetics of these biomarkers over time are also considered.

Respiratory infection management guidelines recommend stratifying patients with CAP based on the predicted risk of mortality using risk scores, such as the CURB-65 $[13,15,16]$. However, clinical risk scores are somewhat limited in their practicality in routine clinical practice and carry the risk of miscalibration due to different patient populations and therefore have only moderate operational utility [17]. As a consequence, there is heightened interest in the development of additional prognostication parameters based on newly identified biomarkers that are objectively and rapidly measurable, responsive to clinical recovery, and add relevant, reliable, and real-time information [18-20]. Different studies have evaluated the prognostic potential of PCT in patients with CAP [20-25]. Some of these studies have found that PCT levels only have moderate prognostic accuracy with regard to prediction of mortality. In a large study from the US, most of the benefit of adding PCT levels to existing prediction rules was found in patients with high risk as assessed using a clinical severity score (the PSI) [23]. A low PCT level $(<0.1 \mathrm{mg} / \mathrm{L})$ almost always excluded mortality in highrisk patients. A previous Swiss study using the ProHOSP patient cohort showed that simply measuring the initial PCT level did not improve clinical score for mortality but that following the kinetics of PCT did so, with falling levels demonstrating improved clinical outcomes during followup [26]. The same study found that PCT can better predict serious events, such as ICU admission and complications of CAP (e.g., empyema). As a predictor of these outcomes, PCT could significantly improve clinical risk scores such as the PSI and CURB-65, a finding that was confirmed by our results. A study of low-risk CAP patients showed PCT to be a good predictor of mortality and to also significantly improve clinical risk scores [21]. The current report further extends the findings of these studies by also comparing 
Table 4 Prognostic value of the CURB-65 score alone and in combination with biomarker levels.

\begin{tabular}{|c|c|c|c|}
\hline \multirow[t]{2}{*}{ Biomarkers } & \multirow[b]{2}{*}{$\mathrm{n}$ total } & \multirow{2}{*}{$\begin{array}{r}\text { Mortality } \\
\text { AUC }(95 \% \mathrm{Cl})\end{array}$} & \multirow{2}{*}{$\begin{array}{r}\begin{array}{r}\text { Adverse clinical } \\
\text { outcomes }\end{array} \\
\text { AUC }(95 \% \mathrm{Cl})\end{array}$} \\
\hline & & & \\
\hline \multicolumn{4}{|l|}{ Day 1} \\
\hline CURB-65 & 917 & $0.72(0.66-0.78)$ & $0.68(0.64-0.73)$ \\
\hline CURB-65+PCT & 917 & $0.73(0.67-0.79)$ & $0.71(0.66-0.76)$ \\
\hline CURB-65+CRP & 917 & $0.72(0.66-0.78)$ & $0.73(0.68-0.78)$ \\
\hline CURB-65+WBC & 917 & $0.73(0.67-0.79)$ & $0.68(0.63-0.73)$ \\
\hline All & 917 & $0.73(0.67-0.79)$ & $0.74(0.69-0.78)$ \\
\hline \multicolumn{4}{|l|}{ Day 3} \\
\hline CURB-65+PCT & 644 & $0.74(0.66-0.83)$ & $0.71(0.65-0.77)$ \\
\hline CURB-65+CRP & 644 & $0.74(0.65-0.83)$ & $0.73(0.67-0.80)$ \\
\hline CURB-65+WBC & 644 & $0.76(0.69-0.84)$ & $0.68(0.62-0.74)$ \\
\hline All & 644 & $0.76(0.68-0.84)$ & $0.75(0.69-0.81)$ \\
\hline \multicolumn{4}{|l|}{ Day 5} \\
\hline CURB-65+PCT & 464 & $0.71(0.62-0.81)$ & $0.75(0.70-0.81)$ \\
\hline CURB-65+CRP & 464 & $0.71(0.60-0.83)$ & $0.76(0.69-0.82)$ \\
\hline CURB-65+WBC & 464 & $0.69(0.58-0.80)$ & $0.74(0.68-0.80)$ \\
\hline All & 464 & $0.73(0.63-0.83)$ & $0.79(0.74-0.84)$ \\
\hline \multicolumn{4}{|l|}{ Day 7} \\
\hline CURB-65+PCT & 371 & $0.77(0.65-0.89)$ & $0.71(0.64-0.78)$ \\
\hline CURB-65+CRP & 371 & $0.82(0.72-0.92)$ & $0.68(0.61-0.76)$ \\
\hline CURB-65+WBC & 371 & $0.74(0.62-0.86)$ & $0.72(0.66-0.79)$ \\
\hline All & 371 & $0.85(0.80-0.93)$ & $0.75(0.68-0.81)$ \\
\hline \multicolumn{4}{|l|}{ Difference day $1-3$} \\
\hline CURB-65+PCT & 640 & $0.68(0.58-0.78)$ & $0.54(0.47-0.62)$ \\
\hline CURB-65+CRP & 640 & $0.63(0.53-0.72)$ & $0.52(0.46-0.59)$ \\
\hline CURB-65+WBC & 640 & $0.70(0.59-0.81)$ & $0.69(0.62-0.75)$ \\
\hline All & 640 & $0.78(0.71-0.85)$ & $0.70(0.63-0.76)$ \\
\hline \multicolumn{4}{|l|}{ Difference day $1-5$} \\
\hline CURB-65+PCT & 461 & $0.65(0.50-0.79)$ & $0.55(0.47-0.64)$ \\
\hline CURB-65+CRP & 461 & $0.72(0.60-0.85)$ & $0.60(0.53-0.68)$ \\
\hline CURB-65+WBC & 461 & $0.61(0.49-0.74)$ & $0.71(0.64-0.77)$ \\
\hline All & 461 & $0.70(0.59-0.80)$ & $0.74(0.68-0.80)$ \\
\hline \multicolumn{4}{|l|}{ Difference day 1-7 } \\
\hline CURB-65+PCT & 369 & $0.62(0.45-0.79)$ & $0.50(0.41-0.59)$ \\
\hline CURB-65+CRP & 369 & $0.79(0.66-0.92)$ & $0.54(0.46-0.62)$ \\
\hline CURB-65+WBC & 369 & $0.62(0.43-0.81)$ & $0.69(0.62-0.76)$ \\
\hline All & 369 & $0.76(0.67-0.86)$ & $0.71(0.64-0.79)$ \\
\hline
\end{tabular}

All, CURB-65+PCT+CRP+WBC; AUC, area under the curve; $95 \% \mathrm{Cl}$, 95\% confidence intervals; CRP, C-reactive protein; ICU, intensive care unit; PCT, procalcitonin; WBC, white blood cells.

PCT to other inflammatory markers and their combination with clinical CAP risk scores.

Similar to our findings but with more statistical power, a large study from Germany including 1671 CAP patients found that PCT levels at admission predict the outcome of CAP with a similar prognostic accuracy as the CRB-65 score and with a higher prognostic accuracy compared with CRP and WBC [27]. The AUC for mortality for PCT was 0.80 (95\% CI 0.75-0.84), as compared to an AUC of 0.79 (0.74-0.84) for CRB-65, 0.62 (0.54-0.68) for CRP, and
0.61 (0.54-0.68) for WBC. This study also documented the added utility of PCT in the identification of patients at very low risk of death despite increased CRB-65 scores. Another study from France that included 100 patients admitted to the ICU with CAP reported that increased PCT from day 1 to day 3 in patients with severe CAP is suggestive of a poor prognosis and a PCT level $<0.95 \mathrm{ng} / \mathrm{mL}$ on day 3 in intubated patients is associated with a better outcome [28]. The kinetics of biomarkers on follow-up also has additional prognostic accuracy in our study. The CRP value for mortality was not informative, contrary to the findings of a previous study [7].

Improved prediction of 30-day mortality in CAP patients by using a combination of CRP in conjunction with the PSI, CURB-65, and CRB65 clinical severity indices has also been described [7]. We did not find a significant correlation of CRP levels at admission with outcome and can confirm the results of other studies documenting the poor prognosis value of CRP levels [29, 30]. Kruger et al. found PCT, CRP, and WBC to be predictive of 28-day mortality exclusively in patients without antimicrobial pretreatment [21].

Our study had limitations. This cohort included mainly inpatients. Therefore it is not possible to determine whether the results would also be applicable to lower risk outpatients with CAP. Quantification of PCT levels on days 3, 5, and 7 was based on patient availability and contributed to information not being complete in the case of a few patients. The potential impact of antimicrobial pre-treatment on marker levels was not considered in this analysis. Moreover, this was a secondary analysis of a previously published randomized study, and exclusion criteria and the resulting non-participation of some patients may limit the external validity of our findings. Specifically, patients with immunosuppression and chronic infection were not included, which limits the generalizability of our results in regard to this important patient population. Finally, our study was an observational, exploratory study and, thus, hypothesis generating. Future interventional studies should ultimately test the potential of a biomarker-enhanced clinical risk score strategy on patient outcomes. As good examples in this regard, two recently published trials found improved outcomes following use of the inflammatory biomarker ProADM (ProAdrenomedullin) in addition to CURB-65 to facilitate site-of-care decisions in CAP [31, 32].

\section{Conclusions}

This study demonstrated that PCT, and to a lesser degree CRP, provide prognostic information on CAP outcomes, 
particularly when their kinetics are taken into consideration and when adverse clinical outcomes are also considered instead of mortality alone. The most important improvements were found on days 5 and 7 for prediction of both survival and adverse clinical outcomes. Future randomized trials should assess whether integration of initial and follow-up biomarker levels results in improved decision making by physicians regarding initial site of care and early discharge from the hospital.

Acknowledgments: We are grateful to all local physicians, nursing staff, and patients who participated in this study. We especially thank the staff of the emergency room, medical clinics, and central laboratories of the University Hospital Basel, the "Kantonsspitaeler" Liestal, Aarau, Luzern, and Muensterlingen, and the "Bürgerspital" Solothurn for their very helpful assistance, patience, and technical support. We thank the members of the Data Safety and Monitoring Board, namely A. P. Perruchoud, S. Harbarth, and A. Azzola and all members of the ProHOSP Study Group, namely Robert Thomann, MD, Claudine Falconnier, MD, Marcel Wolbers, PhD, Isabelle Widmer, MD, Stefanie Neidert, MD, Thomas Fricker, MD, Claudine Blum, MD, Ursula Schild, RN, Katharina Regez, RN, Rita Bossart, RN, Ronald Schoenenberger, MD, Christoph Henzen, MD, Claus Hoess, MD, Heiner C. Bucher, MD, Ayesha Chaudri, Jeannine Haeuptle, Roya Zarbosky, Rico Fiumefreddo, Melanie Wieland, RN, Charly Nusbaumer, MD, Andres Christ, MD, Roland Bingisser, MD, Kristian Schneider, RN, Christine Vincenzi, RN, Michael Kleinknecht, RN, Brigitte Walz, PhD, Verena Briner, MD, Dieter Conen, MD, Andreas Huber, MD, Jody Staehelin, MD, Chantal Bruehlhardt, RN, Ruth Luginbuehl, RN, Agnes Muehlemann, $\mathrm{PhD}$, Ineke lambinon, Max Zueger, MD, D. Conen, MD, M. Wieland, RN, C. Nusbaumer, MD, C. Bruehlhardt, RN, R. Luginbuehl, RN, A. Huber, MD, B. Walz, RN, M. Zueger, MD, and M.L. Stubbs. Editorial support was provided by Prasad Kulkarni, PhD, CMPP, of Asclepius Medical Communications LLC, Ridgewood, NJ, USA and was funded by the authors.

Author contributions: All the authors have accepted responsibility for the entire content of this submitted manuscript and approved submission.

Financial support: The initial trial was supported by grant SNSF 3200BO-116177/1 and 32003B-135222 from the Swiss National Science Foundation. Prof. Schuetz is supported by the Swiss National Science Foundation (SNSF Professorship, PP00P3_150531 / 1). Prof Christ-Crain is supported by the Swiss National Science Foundation (SNSF Professorship PP0P3_123346).

Employment or leadership: None declared.
Honorarium: Philipp Schuetz, MCC and Beat Mueller have received financial support from BRAHMS/Thermofisher and BioMerieux to attend meetings and have fulfilled speaking engagements. BM has served as a consultant to and received research support from BRAHMS/Thermofisher and BioMerieux. All other authors declare that they have no competing interests.

Competing interest: The funding organization(s) played no role in the study design; in the collection, analysis, and interpretation of data; in the writing of the report; or in the decision to submit the report for publication.

\section{References}

1. Levy MM, Dellinger RP, Townsend SR, Linde-Zwirble WT, Marshall JC, Bion J, et al. The Surviving Sepsis Campaign: results of an international guideline-based performance improvement program targeting severe sepsis. Intens Care Med 2010;36:222-31.

2. Welte T, Torres A, Nathwani D. Clinical and economic burden of community-acquired pneumonia among adults in Europe. Thorax 2012;67:71-9.

3. Schneider SM, Veyres P, Pivot X, Soummer AM, Jambou P, Filippi J, et al. Malnutrition is an independent factor associated with nosocomial infections. Br J Nutr 2004;92:105-11.

4. Beigel JH, Farrar J, Han AM, Hayden FG, Hyer R, de Jong MD, et al. Avian influenza A (H5N1) infection in humans. N Engl J Med 2005;353:1374-85.

5. Chotpitayasunondh T, Ungchusak K, Hanshaoworakul W, Chunsuthiwat S, Sawanpanyalert P, Kijphati R, et al. Human disease from influenza A (H5N1), Thailand, 2004. Emerg Infect Dis 2005;11:201-9.

6. Woodhead M, Blasi F, Ewig S, Garau J, Huchon M, Leven M, et al. Guidelines for the management of adult lower respiratory tract infections. Clin Microbiol Infect 2011;17(Suppl 6):E1-59.

7. Menendez R, Martinez R, Reyes S, Mensa J, Filella X, Marcos MA, et al. Biomarkers improve mortality prediction by prognostic scales in community-acquired pneumonia. Thorax 2009;64:587-91.

8. Schuetz P, Christ-Crain M, Muller B. Procalcitonin and other biomarkers to improve assessment and antibiotic stewardship in infections - hope for hype? Swiss Med Wkly 2009;139:318-26.

9. Schuetz P, Christ-Crain M, Wolbers M, Schild U, Thomann R, Falconnier $C$, et al. Procalcitonin guided antibiotic therapy and hospitalization in patients with lower respiratory tract infections: a prospective, multicenter, randomized controlled trial. BMC Health Serv Res 2007;7:102.

10. Schuetz P, Christ-Crain M, Thomann R, Falconnier C, Wolbers M, Widmer I, et al. Effect of procalcitonin-based guidelines vs standard guidelines on antibiotic use in lower respiratory tract infections: the ProHOSP randomized controlled trial. J Am Med Assoc 2009;302:1059-66.

11. Fine MJ, Auble TE, Yealy DM, Hanusa BH, Weissfeld LA, Singer DE, et al. A prediction rule to identify low-risk patients with community-acquired pneumonia. N Engl J Med 1997;336:243-50. 
12. Thorpe TC, Wilson ML, Turner JE, DiGuiseppi JL, Willert M, Mirrett S, et al. BacT/Alert: an automated colorimetric microbial detection system. J Clin Microbiol 1990;28:1608-12.

13. Neill AM, Martin IR, Weir R, Anderson R, Chereshsky A, Epton MJ, et al. Community acquired pneumonia: aetiology and usefulness of severity criteria on admission. Thorax 1996;51:1010-6.

14. Capelastegui A. Validation of a predictive rule for the management of community-acquired pneumonia. Eur Respir J 2006;27:151-7.

15. Lim WS, van der Eerden MM, Laing R, Boersma WG, Karalus N, Town GI, et al. Defining community acquired pneumonia severity on presentation to hospital: an international derivation and validation study. Thorax 2003;58:377-82.

16. Niederman MS. Recent advances in community-acquired pneumonia: inpatient and outpatient. Chest 2007;131:1205-15.

17. Schuetz P, Koller M, Christ-Crain M, Steyerberg E, Stolz D, Muller C, et al. Predicting mortality with pneumonia severity scores: importance of model recalibration to local settings. Epidemiol Infect 2008;136:1628-37.

18. Schuetz P, Litke A, Albrich WC, Mueller B. Blood biomarkers for personalized treatment and patient management decisions in community-acquired pneumonia. Curr Opin Infect Dis 2013;26:159-67.

19. Schuetz P, Haubitz S, Mueller B. Do sepsis biomarkers in the emergency room allow transition from bundled sepsis care to personalized patient care? Curr Opin Crit Care 2012;18:341-9.

20. Schuetz P, Amin DN, Greenwald JL. Role of procalcitonin in managing adult patients with respiratory tract infections. Chest 2012;141:1063-73.

21. Kruger S, Ewig S, Kunde J, Hartmann O, Marre R, Suttorp N, et al. Assessment of inflammatory markers in patients with community-acquired pneumonia - influence of antimicrobial pre-treatment results from the German competence network CAPNETZ. Clin Chim Acta 2010;411:1929-34.

22. Haeuptle J, Zaborsky R, Fiumefreddo R, Trampuz A, Steffen I, Frei $R$, et al. Prognostic value of procalcitonin in Legionella pneumonia. Eur J Clin Microbiol Infect Dis 2009;28:55-60.
23. Huang DT, Weissfeld LA, Kellum JA, Yealy DM, Kong L, Martino $M$, et al. Risk prediction with procalcitonin and clinical rules in community-acquired pneumonia. Ann Emerg Med 2008;52:48-58e2.

24. Luyt CE, Guerin V, Combes A, Trouillet JL, Ayed SB, Bernard M, et al. Procalcitonin kinetics as a prognostic marker of ventilatorassociated pneumonia. Am J Respir Crit Care Med 2005;171:48-53.

25. Seligman R, Meisner M, Lisboa TC, Hertz FT, Filippin TB, Fachel JM, et al. Decreases in procalcitonin and C-reactive protein are strong predictors of survival in ventilator-associated pneumonia. Crit Care 2006;10:R125.

26. Schuetz P, Suter-Widmer I, Chaudri A, Christ-Crain M, Zimmerli W, Mueller B, et al. Prognostic value of procalcitonin in community-acquired pneumonia. Eur Respir J 2011;37:384-92.

27. Kruger S, Ewig S, Marre R, Papassotiriou J, Richter K, von Baum H, et al. Procalcitonin predicts patients at low risk of death from community-acquired pneumonia across all CRB-65 classes. Eur Respir J 2008;31:349-55.

28. Boussekey N, Leroy O, Alfandari S, Devos P, Georges H, Guery B. Procalcitonin kinetics in the prognosis of severe communityacquired pneumonia. Intens Care Med 2006;32:469-72.

29. Hausfater P, Juillien G, Madonna-Py B, Haroche J, Bernard M, Riou B. Serum procalcitonin measurement as diagnostic and prognostic marker in febrile adult patients presenting to the emergency department. Crit Care 2007;11:R60.

30. Boussekey N, Leroy O, Georges H, Devos P, d'Escrivan T, Guery B. Diagnostic and prognostic values of admission procalcitonin levels in community-acquired pneumonia in an intensive care unit. Infection 2005;33:257-63.

31. Albrich WC, Ruegger K, Dusemund F, Schuetz P, Arici B, Litke A, et al. Biomarker-enhanced triage in respiratory infections: a proof-of-concept feasibility trial. Eur Respir J 2013;42:1064-75.

32. Albrich WC, Dusemund F, Ruegger K, Christ-Crain M, Zimmerli W, Bregenzer T, et al. Enhancement of CURB65 score with proadrenomedullin (CURB65-A) for outcome prediction in lower respiratory tract infections: derivation of a clinical algorithm. BMC Infect Dis 2011;11:112. 